\title{
Fomento de la "Cultura Científica"en diferentes Grados y desde una perspectiva multidisciplinar. Descubrimientos científicos y su contexto filosófico-social
}

\author{
Irene Sarrión Sos ${ }^{\mathrm{a}}$, Carmen Fagoaga García ${ }^{\mathrm{b}}$, Ángela Moreno Galvez ${ }^{\mathrm{c}}$, Enrique \\ Eduardo Burguete Miguel $^{\mathrm{d}}, \mathrm{M}^{\mathrm{a}}$ Jesús Vega Bello ${ }^{\mathrm{e}}$ Gloría $\mathbf{M}^{\mathrm{a}}$ Castellano Estornell ${ }^{\mathrm{f}}$ \\ a'Universidad Católica de Valencia (irene.sarrion@ucv.es), bUniversidad Católica de Valencia \\ (carmen.fagoaga@ucv.es). ${ }^{c}$ Universidad Católica de Valencia (angela.moreno@ucv.es), ${ }^{d}$ Universidad \\ Católica de Valencia (enrique.burguete@ucv.es) y eUniversidad Católica de Valencia \\ (mj.vega@ucv.es), ${ }^{\mathrm{f}}$ Universidad Católica de Valencia ( gloria.castellano@ucv.es )
}

\begin{abstract}
Scientific concepts taught in university degrees often centre on major scientific discoveries. A consequence of this may be that students develop distorted views of science in practice, placing too much emphasis on the discoveries themselves and the apparent perfect minds that made them.

Scientific research, communication and the application of science are not independent stages, and should be considered holistically as an ever evolving process of knowledge, ideas, theory and practice.

This project aims to help students that write about science, develop an understanding of how science, society and technology are intrinsically linked. Using case studies from different scientific fields, we will examine how science is perceived in a political and social context. Students will be encouraged to enhance their thinking around the perception of science versus reality that will authenticate their documentation of scientific events of the future.
\end{abstract}

Keywords: scientific culture, anthropological-philosophical-social context, news story, scientific journal.

\section{Resumen}

Los contenidos de las asignaturas de carácter científico que se imparten en los Grados Universitarios se centran fundamentalmente en conceptos procedentes de grandes descubrimientos científicos. Sin embargo, los alumnos tienen visiones deformadas de la ciencia ya que se considera que dichos descubrimientos son un producto de mentes perfectas y realidades inmutables.

La investigación científica, la comunicación y la aplicación de la ciencia no son etapas independientes, sino que se debe considerar la ciencia, como una actividad social a través de un proceso multidireccional de conocimientos, prácticas, teorías e ideas.

Este proyecto pretende que los alumnos conozcan que la ciencia, la sociedad y la tecnología no se pueden concebir aisladamente, sino que están intrinsicamente relacionadas. A través del trabajo en equipo y trabajando desde distintos ámbitos científicos y en distintos Grados, hemos pretendido acercar la vida de los científicos al mundo real, situándolos en el contexto 
Fomento de la "Cultura Científica"en diferentes Grados y desde una perspectiva multidisciplinar.Descubrimientos científicos y su contexto filosófico-social

politico- social del momento, para que los alumnos los conozcan mejor y que usando lenguaje periodístico sean los protagonistas que redacten los grandes hitos del momento.

Palabras clave: cultura científica, contexto antropológico-filosófico-social, noticia periodística, revista científica.

\section{Introducción}

Los contenidos de las asignaturas de carácter científico que se imparten en los Grados universitarios, se nutren de los grandes descubrimientos científicos. Los alumnos, sin embargo, acostumbran a tener una visión distorsionada de los mismos, considerando que proceden de mentes perfectas que trabajan en condiciones idílicas y de un progreso científico que, con carácter vectorial y necesario, se sustenta sobre realidades inmutables. De ahí que entiendan el método científico como una suerte de receta constituida por pasos rígidos y secuenciales, sin caer en la cuenta de las dificultades y limitaciones inherentes al ámbito de la investigación. Dificultades y limitaciones que constituyen su gran reto y convierten la investigación científica en una gran aventura vital al servicio del bien común.

Los profesores implicados en este proyecto hemos constatado que nuestros alumnos desconocen, por lo general, la biografía de los grandes investigadores y el contexto familiar y social, histórico y político, antropológico y filosófico en el que desarrollaron sus investigaciones. Desconocen, también, sus principales influencias y, en general, los problemas que hubieron de superar para llevar a cabo sus proyectos. De ahí que hayamos visto la necesidad de acercarles a la realidad del investigador y de promover la consideración de la investigación, la comunicación y la aplicación de la ciencia como realidades interconectadas. La ciencia, así lo entendemos, no es ajena a la realidad social ni progresa como una realidad independiente de ésta. El verdadero progreso no se deja decir en plural (refieriéndose exclusivamente a los progresos científico-técnicos) sino en singular (atendiendo al progreso de la humanidad). La actividad científica es, ante todo, una actividad social y relacional en la que, a través de un intercambio multidireccional de conocimientos, prácticas, teorías e ideas, se alcanzan logros cuyos resultados afectan, de un modo directo, a la vida de las personas y de las sociedades que éstas conforman.

Este proyecto se dirige, por consiguiente, a facilitar la comprensión de la intrínseca relación que existe entre la ciencia y el contexto social de su tiempo, al objeto de paliar la creciente hipostatización del subsistema científico y la escisión de éste respecto del verdadero progreso humano. 
Los alumnos de las asignaturas y titulaciones referenciadas en el epígrafe 3, han conformado equipos de trabajo compuestos por 4 o 5 alumnos para acercarse a la biografía y contexto social de los científicos seleccionados. De este modo, han tomado conciencia de las dificultades a las que se enfrentaron para lograr, más allá de su prestigio personal, la mejora de la vida de sus coetáneos y de las generaciones posteriores. Además, con el uso del lenguaje periodístico, han sido capaces de redactar los descubrimientos en clave de noticia y divulgación científica, en tiempo presente y contextualizando hasta el punto de sentirse protagonistas del momento.

\section{Objetivos}

Los objetivos perseguidos con la realización de este proyecto han sido los siguientes:

* Promover entre los alumnos una "cultura científica" que les permita advertir las interrelaciones que existen entre la ciencia, la sociedad y la tecnología.

* Capacitar a los alumnos para buscar información y realizar estudios bibliométricos en bases de datos de Ciencias experimentales y Ciencias sociales.

* Favorecer en los alumnos el análisis crítico de los descubrimientos científicos en su contexto religioso, filosófico, político y social.

* Conseguir que los alumnos valoren el trabajo en equipo, reconociendo la influencia de los colaboradores e influencias en el logro de todo descubrimiento.

* Capacitar a los alumnos para la divulgación científica por medio de noticias dirigidas a público no especializado.

* Hacer partícipes activos y protagonistas de su propio aprendizaje a los alumnos, permitiéndoles adoptar diferentes roles en el proceso de investigación y potenciando, con el aprendizaje autónomo, el desarrollo de competencias cognitivas y habilidades interpersonales de comunicación.

* Transmitir a los alumnos la importancia de colaborar con otros alumnos y profesores de distintas asignaturas y áreas del conocimiento, especialmente en los ámbitos de las Ciencias experimentales y la Antropología

* Potenciar en los alumnos habilidades de comunicación y transferencia de los resultados de su trabajo a estudiantes de otras asignaturas y Grados.

\section{Desarrollo de la innovación}

Para este proyecto de innovación docente se ha empleado la metodología "flipped classroom" o clase inversa. Ésta, mediante el intercambio en los roles aula/casa y profesor/estudiante, consigue que el estudiante adquiera un papel protagonista en el proceso de la enseñanza, alcanzando destrezas en el aprendizaje autónomo, en el trabajo cooperativo y en el empleo de las nuevas tecnologías. Facilita, además, la adquisición de las competencias básicas de cada una de las asignaturas y Grados que participan en el proyecto, como la capacidad de transmitir información, ideas, problemas y soluciones a un público tanto especializado como no 
Fomento de la "Cultura Cientifica"en diferentes Grados y desde una perspectiva multidisciplinar.Descubrimientos científicos y su contexto filosófico-social

especializado; y la adquisición de competencias generales, como la capacidad para las relaciones interpersonales y el trabajo en equipo; por último, contribuye también a la adquisición de las competencias específicas de cada asignatura.

La metodología "flipped classroom" implica, además, una filosofía que reconcilia la dimensión cognitiva y la dimensión ética de la persona, permitiendo al alumno comprender que los descubrimientos científicos tienen una gran repercusión social y deben tener como finalidad mejorar la vida de los demás.

Esta experiencia piloto tiene como objetivo mejorar el proceso enseñanza-aprendizaje de los estudiantes de las asignaturas y Grados siguientes:

* Doble Grado Biotecnología-Ciencias del Mar: Química orgánica, Antropología.

* Grado Biotecnología: Biotecnología vegetal y animal, Antropología.

* Doble Grado en Nutrición-Enfermería: Química orgánica, Antropología.

* Doble Grado en Ciencias de la Actividad física y Deporte-Nutrición humana y dietética: Fisiología humana, Química orgánica, Antropología.

* Grado en Ciencias de la Actividad Física y Deporte: Bioquímica, Antropología.

\subsection{Elaboración de materiales y recursos didácticos por los profesores}

El profesorado de cada asignatura proporcionó, a principio de curso, el material que describimos a continuación. Este material fue preparado conjuntamente por los profesores en distintas reuniones de coordinación, haciendo coincidir, en todas las asignaturas, los siguientes materiales:

1. Presentación del proyecto en formato Power-Point.

2. Listado de los "Descubrimientos científicos" a elelgir en cada asignatura y Grado. La elección de cada grupo de alumnos se detalla en las tablas del apartado 4.

3. Calendario o cronograma de entrega de actividades.

4. "Ficha del descubrimiento científico" (ANEXO 1). Se trata de una plantilla en la que los alumnos recogieron la siguiente información:

* Título del descubrimiento, contenidos conceptuales y descripción científica.

* Perfil bibliográfico del científico descubridor del mismo: cronología que recoja los principales aspectos de su vida y de su obra, hechos más destacados y formación científica y las principales influencias que recibió.

* Ideas dominantes de la Ciencia en la que se formó: sus maestros, marcos teóricos que existían en su época y que influyeron en su formación, y el estado en que se encontraban los problemas que más tarde abordó.

* Sociedad de su época: contexto social y político que se vivía. Influencia de la sociedad en los desarrollos científicos. Principales acontecimientos. Otros científicos o personas relevantes de la sociedad de su época. 
* Otras aportaciones a la ciencia: Descubrimientos realizados y teorías elaboradas a partir del descubrimiento. Aplicaciones tecnológicas e implicaciones sociales. Establecer un paralelismo cronológico que señale las interrelaciones entre la ciencia, la tecnología y la sociedad.

* Bibliografía utilizada. Libros o artículos de revistas utilizados, materiales o documentos de apoyo entregados por el profesorado.

5. Plantilla de "Noticia de divulgación científica" (ANEXO 2). Con la información recogida en la ficha anterior, los estudiantes prepararon una noticia de divulgación científica.

6. Rubrica de evaluación de nota final. Con la rubrica entregada al inicio de curso, el alumno tuvo conocimiento, en todo momento, de los criterios de evaluación. (ANEXO 3).

7. Posteriormente, con todas las noticias se publicó una Revista o Periódico digital e impreso (ANEXO 4). Este documento se mostró en la plataforma docente de todas las asignaturas y Grados. Además, se entregó a cada grupo un ejemplar impreso de la revista con la noticia que había preparado

8. Finalmente, se elaboró por parte del profesorado una encuesta para valorar la aceptación del trabajo y la repercusión del mismo en el alumnado. (ANEXO 5)

\subsection{Constitución de los equipos de alumnos participantes}

Por libre asociación, se constituyeron equipos de entre 4 y 5 alumnos para la elaboración de la "Ficha del descubrimiento" y de la "Noticia de divulgación científica". Cada grupo seleccionó, entre los propuestos en su asignatura, el investigador y descubrimiento que quería trabajar. En algunos casos, los alumnos presentaron investigadores de su interés que no estaban en la lista propuesta por su profesor. La selección y adjudicación de investigadores se realizó a través de una actividad creada $a d$ hoc en el Campus virtual UCVnet.

Al tratarse de una tarea no desarrollada en el aula, se admitió de modo excepcional la constitución de equipos más pequeños que facilitasen las reuniones de trabajo de aquellos alumnos con dificultades asociadas a su lugar de residencia o a sus obligaciones laborales.

La dinámica de trabajo cooperativo ha facilitado que los alumnos, en su mayoría de primer curso de Grado, asimilen la importancia de una adecuada coordinación, así como la aceptación de la valoración crítica, sugerencias y apoyo de los restantes miembros de su equipo de trabajo. El carácter novedoso del proyecto y la curiosidad que despierta el contexto en que se llevaron a cabo los descubrimientos propuestos, ha incidido en la participación activa de los alumnos en el desarrollo del proyecto, constituyendo un importante valor añadido al proceso de aprendizaje que se desarrolla en las sesiones de aula. Además, la experiencia de trabajo cooperativo les ha permitido valorar adecuadamente la relevancia que tuvieron, para el descubridor objeto de estudio, la colaboración de su equipo de trabajo, las 
Fomento de la "Cultura Cientifica"en diferentes Grados y desde una perspectiva multidisciplinar.Descubrimientos científicos y su contexto filosófico-social

influencias académicas y familiares y, en general, el contexto económico, social, ideológico, politico y religioso de su época.

La interrelación de todos estos factores ha incidido en la irrupción, en el imaginario del alumno, de una "nueva imagen" de la tarea científica. Una imagen humanizada en su raíz, en su desarrollo y en sus consecuencias, tal como apuntan investigadores como Glagliardi y Giordan (1986), Matthews (1994) y Briceño (2001). Todos ellos sostienen, unánimemente, que conocer la historia de la ciencia puede humanizar su enseñanza, haciendo las clases más activas y reflexivas y contribuyendo, así, a una mayor comprensión de los contenidos científicos.

En el proyecto se han implicado un total de 172 alumnos, distribuidos en 41 grupos según se muestra en la Tabla 1.

Tabla 1. Número de alumnos por asignatura y Grado

\section{NÚMERO DE ALUMNOS Y GRUPOS POR ASIGNATURA Y GRADO}

\begin{tabular}{|c|c|c|c|c|}
\hline ASIGNATURA & GRADO/S & № ALUMNOS & № GRUPOS & PROFESOR/A \\
\hline \multirow{4}{*}{$\begin{array}{l}\text { QUÍMICA } \\
\text { ORGÁNICA }\end{array}$} & BIOTECNOLOGÍA & 32 & 8 & \multirow{4}{*}{ Gloria Castellano } \\
\hline & $\begin{array}{c}\text { BIOECNOLOGÍA-CC. } \\
\text { DEL MAR }\end{array}$ & 13 & 3 & \\
\hline & NUTRICION & 33 & 9 & \\
\hline & NUTRICIÓN-CAFD & 8 & 2 & \\
\hline $\begin{array}{c}\text { BIOLOGÍA VEGETAL } \\
\text { Y ANIMAL }\end{array}$ & BIOTECNOLOGÍA & 9 & 3 & Carmen Fagoaga \\
\hline $\begin{array}{l}\text { FISIOLOGÍA } \\
\text { HUMANA }\end{array}$ & $\begin{array}{c}\text { CAFD } \\
\text { NUTRICIÓN-CAFD }\end{array}$ & 37 & 8 & Irene Sarrión \\
\hline BIOQUÍMICA & NUTRICIÓN & 40 & 8 & $\mathrm{M}^{\mathrm{a}}$ Jesús Vega \\
\hline TOTAL & & 172 & 41 & \\
\hline
\end{tabular}

PROFESOR TRANSVERSALA TODOS LOS GRADOS: Enrique Burguete

\subsection{Preparación y elaboración de las fichas por parte de los alumnos}

A través de la aplicación informática Google-Docs, los integrantes de cada equipo de trabajo han compartido los documentos obtenidos mediante su investigación bibliográfica.

Tras seleccionar y sintetizar aquellos que les han servido de base para la elaboración de la "Ficha del Descubrimiento", los equipos han discriminado la información más relevante aportada por cada uno de ellos, consensuando lo que querían destacar. Se ha contribuido, así, a desarrollar su espíritu crítico, sus habilidades comunicativas y su competencia de análisis y síntesis.

Para analizar adecuadamente el context de la época en que se produjeron los descubrimientos estudiados, se ha contado con el asesoramiento del profesor de Antropología y de las profesoras de las asignaturas implicadas en el proyecto. Con su ayuda, los alumnos han avanzado en la comprensión de la ciencia como un proceso más amplio que la mera y rígida aplicación de un protocolo, reconociendo las limitaciones que debe superar todo investigador. 
Los alumnos han volcado la información seleccionada en la "Ficha del Descubrimiento" reseñada en el epígrafe 3.1 de este documento y documentada en el ANEXO 1, que presenta el modelo de ficha y un ejemplo de su cumplimentación por parte de uno de los grupos de trabajo.

\subsection{Evaluación y calificación de las fichas por los profesores siguiendo la rúbrica diseñada}

La evaluación de la "Ficha del Descubrimiento" se ha llevado a cabo de acuerdo con una rúbrica común elaborada por el equipo docente (ANEXO 3). En ella se valora el contenido, la presentación y la ortografía. Previamente a la presentación del trabajo se facilitó a los alumnos suficiente información sobre las pautas y plazos de entrega del mismo, así como de los criterios para su evaluación.

\subsection{Preparación y realización de las noticias por parte de los alumnos}

La continua retroalimentación y el seguimiento del trabajo de los alumnos por parte del equipo docente, así como la plantilla que les facilitó en la primera fase del proyecto (ANEXO 2), ha contruibuido a salvar las dificultades inherentes a esta fase del proyecto. Dificultades que abarcan desde la necesaria uniformidad en la presentación de todas las noticias, hasta la elección de un título y subtítulo que resulten atractivos e inviten a la lectura de la noticia por parte de un público no especializado. Y que incluyen también, la necesidad de comprimir la información contenida en la Ficha del descubrimiento para trasladarla a la noticia.

\subsection{Evaluación y calificación de las noticias por los profesores siguiendo la rúbrica}

La rúbrica de evaluación (ANEXO 3) incluye la valoración de la" Ficha del descubrimiento" y de la "Noticia". En esta rúbrica se pondera, en ambas, la estructura del trabajo escrito, los contenidos conceptuales y la expresión escrita. La nota final se calculó dando un valor de 65\% a la Ficha del Descubrimiento científico, por tratarse de un trabajo más extenso. El resto, se asignó a la noticia (35\%) Aunque tanto profesores como alumnos estuvieron de acuerdo con esta ponderación, la preparación de la noticia de divulgación supuso un esfuerzo importante por la dificultad de sintetizar la información recogida en la Ficha del descubrimiento.

Una vez obtenida la nota final con la misma rúbrica para todas las asignaturas, en cada asignatura se aplicó la valoración que figura para este trabajo en la Guía Docente

\subsection{Elaboración de la Revista de divulgación científica por los profesores participantes}

Tras la elaboración, corrección y calificación de cada una de las noticias elaboradas por los alumnos, se ha procedido al montaje de una "Revista o Periódico digital" (ANEXO 4). Ésta consta de una una portada en la que se detalla el nombre de los alumnos participantes en el proyecto, así como las asignaturas, Grados y profesores implicados en el mismo. A continuación se incluye un índice que recoge, por orden alfabético, la totalidad de los descubrimientos científicos y de los investigadores recogidos en la revista. El ANEXO 4 
incluye, además de la portada e índice de la revista, un ejemplo de noticia incluída en la revista digital.

Además de la revista digital, se han impreso a color un total de 55 ejemplares, repartiéndose uno a cada grupo participante y otro a cada profesor implicado en el proyecto. El resto de ejemplares están a disposición del público interesado en las bibliotecas de las distintas Facultades donde se imparten los Grados que han participado en su elaboración. El coste de la impresón de la revista ha sido de $600 €$.

Una vez en posesión de su ejemplar, los alumnos de los distintos Grados y asignaturas implicados en el proyecto han compartido su experiencia. En general, han coincidido en resaltar el enriquecimiento conceptual que ha supuesto su realización y, sobre todo, la ampliación de su vision sobre la labor del investigador y sobre la interrelación de la ciencia con la mejora de la vida personal y social.

\section{Resultados}

En los epígrafes que siguen, se detalla la calificación final obtenida por los distintos grupos en cada una de las asignaturas y Grados, detallando la calificación referente a la "Ficha del Descubrimiento" y a la "Noticia" (Tablas 2 - 9). La tabla 10 muestra las calificaciones globales. En la tabla 11 se ofrecen los resultados de la encuesta de valoración del proyecto por parte de los alumnos.

\subsection{Asignatura de Química Orgánica}

Se trata de la asignatura con un índice más alto de participación, tanto en número de alumnos como de Grados implicados. Se ha contado con la participación de 86 alumnos pertenecientes a los Grados de Biotecnología, Ciencias del Mar, Nutrición y CAFD. Las calificaciones globales del proyecto en la Asignatura Química Orgánica se detallan en la Tabla 2. En las Tablas 3-6 se ofrecen las calificaciones en función del Grado en que dicha asignatura implantó el proyecto.

Tabla 2. Calificaciones totales de la ficha y la noticia en la Asignatura de Química Orgánica

TOTALES ASIGNATURA QUÍMICA ORGÁNICA

\begin{tabular}{|l|c|c|c|}
\hline \multicolumn{1}{|c|}{ CALIFICACIONES } & NOTAS FICHA & NOTAS NOTICIA & NOTAS TOTALES \\
\hline SOBRESALENTES & $24,42 \%(21)$ & $53,49 \%(46)$ & $24,42 \%(21)$ \\
\hline NOTABLES & $30,23 \%(26)$ & $27,91 \%(24)$ & $39,53 \%(34)$ \\
\hline APROBADOS & $39,53 \%(34)$ & $12,79 \%(11)$ & $36,04 \%(31)$ \\
\hline SUSPENDIDOS & $5,81 \%(5)$ & $5,81 \%(5)$ & $0 \%(0)$ \\
\hline
\end{tabular}

\section{* Total de alumnos que han participado: 86}


Irene Sarrión Sos, Carmen Fagoaga Garcia, Ángela Moreno Galvez, Enrique Eduardo Burguete Miguel, $M^{a}$ Jesús Vega Bello y Gloría $M^{a}$ Castellano Estornell

Tabla 3. Calificación de la ficha y la noticia en la Asignatura de Química Orgánica en el Grado de Biotecnología.

QUÍMICA ORGÁNICA. GRADO BIOTECNOLOGÍA

\begin{tabular}{|c|l|l|l|l|}
\hline GRUPO & DESCUBRIMIENTO & NOTA FICHA & $\begin{array}{l}\text { NOTA NOTICIA } \\
\text { (SEGUNDA } \\
\text { ENTREGA) }\end{array}$ & $\begin{array}{l}\text { NOTA } \\
\text { TOTAL }\end{array}$ \\
\hline 1 & REACCIÓN DIELS-ALDER. Otto Paul Hermann Diels & 9,67 & 10 & 9,78 \\
\hline 2 & $\begin{array}{l}\text { ESTRUCTURA DE MOLÉCULAS COMPLEJAS POR } \\
\text { CRISTALOGRAFÍA DE RAYOS X. Dorothy Crowfoot Hodgkin }\end{array}$ & 7,66 & 7,75 & 7,7 \\
\hline 3 & ESTERES, TINTES Y AZÚCARES. Hermann Emil Fischer. & 9,3 & 9 & 9,21 \\
\hline 5 & ÁCIDO LISÉRGICO. Albert Hofmann & 9,67 & 9,61 \\
\hline 6 & $\begin{array}{l}\text { REGLA DE MAKÓVNIKOV Vladímir Vasílievich } \\
\text { Markóvnikov. }\end{array}$ & 8,1625 & 9,58 \\
\hline 7 & $\begin{array}{l}\text { HIDROGENACIÓN CATALÍTICA ESTEREOSELECTIVA. Paul } \\
\text { Sabatier }\end{array}$ & 9,17 & 10 & 9,46 \\
\hline 8 & SÍNTESIS DE LA COCAÍNA. Richard Martin Willstätter & 4,83 & 10 & 6,64 \\
\hline
\end{tabular}

\begin{tabular}{|l|c|c|c|}
\hline \multicolumn{1}{|c|}{ CALIFICACIONES } & NOTAS FICHA & NOTAS NOTICIA & NOTAS TOTALES \\
\hline SOBRESALIENTES & $56,25 \%(18)$ & $78,13 \%(25)$ & $56,25 \%(18)$ \\
\hline NOTABLES & $28,13 \%(9)$ & $12,50 \%(4)$ & $28,13 \%(9)$ \\
\hline APROBADOS & $0 \%(0)$ & $9,38 \%(3)$ & $15,63 \%(5)$ \\
\hline SUSPENDIDOS & $15,63 \%(5)$ & $0 \%(0)$ & $0 \%(0)$ \\
\hline
\end{tabular}

Total Participantes: 32

Tabla 4. Calificación de la ficha y la noticia en la Asignatura de Química Orgánica en el doble Grado de Biotecnología-Ciencias del Mar

\section{QUÍMICA ORGÁNICA_DOBLE GRADO BIOTECNOLOGÍA-CIENCIAS DEL MAR}

\begin{tabular}{|c|l|c|c|c|}
\hline GRUPO & DESCUBRIMIENTO & NOTA FICHA & $\begin{array}{l}\text { NOTA NOTICIA } \\
\text { (SEGUNDA } \\
\text { ENTREGA) }\end{array}$ & $\begin{array}{l}\text { NOTA } \\
\text { TOTAL }\end{array}$ \\
\hline 1 & REACCIÓN BORODIN-HUNSDIECKER. Aleksandr Borodín & 6,67 & 10 & 7,83 \\
\hline 2 & HIDROBORACIÓN DE ALQUENOS. Herbert Charles Brown & 6,67 & 5,0 & 6,08 \\
\hline 3 & REACCIÓN DE MANNICH. Carl Mannich & 8,00 & 8,58 & 8,6 \\
\hline
\end{tabular}

\begin{tabular}{|l|c|c|c|}
\hline \multicolumn{1}{|c|}{ CALIFICACIONES } & NOTAS FICHA & NOTAS NOTICIA & NOTAS TOTALES \\
\hline SOBRESALIENTES & $0 \% 0()$ & $38,46 \%(5)$ & $0 \%(0)$ \\
\hline NOTABLES & $30,77 \%(4)$ & $30,77 \%(4)$ & $38,46 \%(5)$ \\
\hline APROBADOS & $69,23 \%(9)$ & $53,85 \%(4)$ & $61,54 \%(8)$ \\
\hline SUSPENDIDOS & $0 \%(0)$ & $0 \%(0)$ & $0 \%(0)$ \\
\hline
\end{tabular}

* Total de alumnos que han participado: 13 
Fomento de la "Cultura Cientifica"en diferentes Grados y desde una perspectiva multidisciplinar.Descubrimientos científicos y su contexto filosófico-social

Tabla 5. Calificación de la ficha y la noticia en la Asignatura de Química Orgánica en el Grado de Nutrición

\section{QUÍMICA ORGÁNICA_GRADO NUTRICIÓN}

\begin{tabular}{|c|c|c|c|c|}
\hline & DESCUBRIMIENTO & NOTA FICHA & $\begin{array}{l}\text { NOTA NOTICIA } \\
\text { (SEGUNDA } \\
\text { ENTREGA) } \\
\end{array}$ & $\begin{array}{l}\text { NOTA } \\
\text { TOTAL }\end{array}$ \\
\hline 1 & REACCIÓN ALDÓLICA. Aleksandr Borodín & 7,00 & 3,50 & 5,78 \\
\hline 2 & REACTIVOS GRIGNARD. Victor Grignard. & 8,50 & 9,5 & 8,85 \\
\hline 3 & SÍNTESIS DE ÉSTERES. Hermann Emil Fischer & 6,2 & 7,00 & 6,46 \\
\hline 4 & CICLOHEXANO. Hermann Sachse & 9,17 & 8,75 & 9,03 \\
\hline 5 & $\begin{array}{l}\text { SÍNTESIS FENOFTALEINA, ASPIRINA Y ÁCIDO BARBITÚRICO.Johann } \\
\text { Friedrich Wilhelm Ritter Von Baeyer }\end{array}$ & 7,17 & 9,50 & 7,98 \\
\hline 6 & SÍNTESIS DE WILLIAMSON. Alexander William Williamson & 5,33 & 6,50 & 5,74 \\
\hline 7 & $\begin{array}{l}\text { REACCIONES DE SUSTITUCIÓN NUCLEÓFILA SN1 Y SN2. Alexander } \\
\text { William Williamson }\end{array}$ & 6,50 & 9,50 & 7,55 \\
\hline 8 & SÍNTESIS DE WURTZ. Charles-Adolphe Wurtz & 5,50 & 7,17 & 6,08 \\
\hline 9 & CATALIZADOR ZIEGLER-NATTA. Karl Ziegler & 6,67 & 9,5 & 7,66 \\
\hline
\end{tabular}

\begin{tabular}{|l|c|c|c|}
\hline \multicolumn{1}{|c|}{ CALIFICACIONES } & NOTAS FICHA & NOTAS NOTICIA & NOTAS TOTALES \\
\hline SOBRESALIENTES & $9,1 \%(3)$ & $36,36 \%(12)$ & $9,1 \%(3)$ \\
\hline NOTABLES & $39,39 \%(13)$ & $39,39 \%(12)$ & $36,36 \%(12)$ \\
\hline APROBADOS & $51,51 \%(17)$ & $12,12 \%(4)$ & $54,54 \%(18)$ \\
\hline SUSPENDIDOS & $0 \%(0)$ & $15,15 \%(5)$ & $0 \%(0)$ \\
\hline
\end{tabular}

* Total de alumnos que han participado: 33

Tabla 6. Calificación de la ficha y la noticia en la Asignatura de Química Orgánica en el doble Grado de Nutrición y CAFD

\section{QUÍMICA ORGÁNICA_GRADO NUTRICIÓN-CAFD:}

\begin{tabular}{|c|l|c|c|c|}
\hline GRUPO & \multicolumn{1}{|c|}{ DESCUBRIMIENTO } & NOTA FICHA & $\begin{array}{c}\text { NOTA NOTICIA } \\
\text { (SEGUNDA ENTREGA) }\end{array}$ & NOTA TOTAL \\
\hline 1 & PROYECCIONES DE FISHER. Hermann Emil Fischer. & 6,83 & 10 & 7,94 \\
\hline 2 & MOLÉCULA DEL BENCENO. Friedich August Kekulé & 6,83 & 8,66 & 7,48 \\
\hline
\end{tabular}

\begin{tabular}{|l|c|c|c|}
\hline \multicolumn{1}{|c|}{ CALIFICACIONES } & NOTAS FICHA & NOTAS NOTICIA & NOTAS TOTALES \\
\hline SOBRESALIENTES & $0 \%(0)$ & $50 \%(4)$ & $0 \%(0)$ \\
\hline NOTABLES & $0 \%(0)$ & $50 \%(4)$ & $100 \%(8)$ \\
\hline APROBADOS & $100 \%(8)$ & $0 \%(0)$ & $0 \%(0)$ \\
\hline SUSPENDIDOS & $0 \%(0)$ & $0 \%(0)$ & $0 \%(0)$ \\
\hline
\end{tabular}

\subsection{Asignatura de Fisiología Humana}

En la asignatura de Fisiología Humana, que se imparte en el Grado en Ciencias de la Actividad Física y el Deporte, han participado 37 alumnos repartidos en un total de 8 grupos. Sus calificaciones se muestran en la Tabla 7. 
Irene Sarrión Sos, Carmen Fagoaga García, Ángela Moreno Galvez, Enrique Eduardo Burguete Miguel, $M^{a}$ Jesús Vega Bello y Gloría $M^{a}$ Castellano Estornell

Tabla 7. Calificación de la ficha y la noticia en la Asignatura de Fisiología humana en el Grado de CAFD

\section{FISIOLOGÍA HUMANA_CAFD GRUPO D}

\begin{tabular}{|c|c|c|c|c|}
\hline GRUPO & DESCUBRIMIENTO & NOTA FICHA & $\begin{array}{l}\text { NOTA NOTICIA } \\
\text { (SEGUNDA ENTREGA) }\end{array}$ & NOTA TOTAL \\
\hline 1 & $\begin{array}{l}\text { GRUPOS SANGUÍNEOS Karl Landsteiner (1868-1943). } \\
\text { EEUU }\end{array}$ & 9,5 & 8,7 & 9,2 \\
\hline 2 & $\begin{array}{l}\text { DOCTRINA DE LA NEURONA Santiago Ramón y Cajal } \\
\text { (1852-1934). Espafía. }\end{array}$ & 4,8 & 6,9 & 5,6 \\
\hline 3 & PENICILINA Alexander Fleming (1881-1955). Escocia & 6,5 & 9,25 & 7,5 \\
\hline 4 & $\begin{array}{l}\text { BACTERIÓFAGO LAMBDA Esther Lederberg } \\
(1922-2006) . E E U U\end{array}$ & 6,2 & 7,66 & 6,7 \\
\hline 5 & $\begin{array}{l}\text { VACUNA CONTRA LA VIRUELA Edward Jenner } \\
(1749-1823) . \text { Inglaterra }\end{array}$ & 8,5 & 10 & 9,025 \\
\hline 6 & $\begin{array}{l}\text { PRIMER TRATAMIENDO CONTRA LA LEUCEMIA Gertrude } \\
\text { Belle Elion (1918-1999). EEUU. }\end{array}$ & 8,66 & 8,58 & 8,6 \\
\hline 7 & PASTEURIZACIÓN Louis Pasteur (1822-1895). Francia & 6 & 9,33 & 7,16 \\
\hline 8 & $\begin{array}{l}\text { ESTRUCTURA DE LA DOBLE HÉLCE DEL ADN Rosalind } \\
\text { Franklin (1920-1958). Inglaterra }\end{array}$ & 7,66 & 7,75 & 7,7 \\
\hline
\end{tabular}

\begin{tabular}{|l|c|c|c|}
\hline \multicolumn{1}{|c|}{ CAUFICACIONES } & NOTAS FICHA & NOTAS NOIICIA & NOTAS TOTALES \\
\hline SOBRESALIENTES & $12,5 \%(1)$ & $37,5 \%(3)$ & $25 \%(2)$ \\
\hline NOTABLES & $37,5 \%(3)$ & $50 \%(4)$ & $50 \%(4)$ \\
\hline APROBADOS & $37,5 \%(3)$ & $12,5 \%(1)$ & $25 \%(2)$ \\
\hline SUSPENDIDOS & $12,5 \%(1)$ & $0 \%(0)$ & $0 \%(0)$ \\
\hline
\end{tabular}

* Total de alumnos que han participado: 37

\subsection{Asignatura de Bioquímica en el Grado de Nutrición}

En la asignatura de Bioquímica, impartida en el Grado de Nutrición, han participado 40 alumnos repartidos en 8 grupos. Sus calificaciones se muestran en la Tabla 8.

Tabla 8. Calificación de la ficha y la noticia en la Asignatura de Bioquímia en el Grado de Nutrición

\section{BIOQUÍMICA_GRADO DE NUTRICIÓN}

\begin{tabular}{|c|l|c|c|c|}
\hline GRUPO & \multicolumn{1}{|c|}{ DESCUBRIMIENTO } & \multicolumn{1}{|c|}{ NOTA FICHA } & \multicolumn{1}{|c|}{$\begin{array}{c}\text { NOTA NOTICIA } \\
\text { (SEGUNDA ENTREGA) }\end{array}$} & NOTA TOTAL \\
\hline 1 & $\begin{array}{l}\text { CICLO DE CORI Carl Ferdinand Cori (1896-1984). } \\
\text { Checoslovaquia }\end{array}$ & 8 & 6,3 & 7,4 \\
\hline 2 & $\begin{array}{l}\text { ESTRUCTURA MOLECULAR DEL ADN Francis Crick (1916-2004). } \\
\text { Gran Bretaria }\end{array}$ & 5,83 & 6,58 & 6,1 \\
\hline 3 & CICLO DE KREBS Hans Adolf Krebs (1900-1981). Alemania & 7,5 & 6,33 & 7,1 \\
\hline 4 & $\begin{array}{l}\text { ESTRUCTURA MOLECULAR DEL ADN James Dewey Watson } \\
\text { (1928).EEUU }\end{array}$ & 4,3 & 6,2 & 5 \\
\hline 5 & $\begin{array}{l}\text { PEPSINA, TRIPSINA, QUIMIOTRIPSINA Y PROTEINAS VÍRICAS } \\
\text { John Howard Northrop (1891-1987).EEUU }\end{array}$ & 3,83 & 7,2 & 5 \\
\hline 6 & $\begin{array}{l}\text { ASIMILACIÓN DEL CO2 POR LAS PLANTAS Melvin Calvin } \\
\text { (1911-1997). EEUU. }\end{array}$ & 5,5 & 6,1 & 5,7 \\
\hline 7 & $\begin{array}{l}\text { GLUCOLISIS Y METABOLISMO DEL ÁCIDO LÁCTICO Otto Fritz } \\
\text { Meyerhof (1884-1933). ALEMANIA }\end{array}$ & 8,33 & 6,75 & 7,8 \\
\hline 8 & $\begin{array}{l}\text { SínTESIS DEL ARN Severo Ochoa de Albornoz (1905-1993). } \\
\text { ESPANA }\end{array}$ & 6,3 & 6 & 6,2 \\
\hline
\end{tabular}

\begin{tabular}{|l|c|c|c|}
\hline \multicolumn{1}{|c|}{ CALIFICACIONES } & NOTAS FICHA & NOTAS NOTICIA & NOTAS TOTALFS \\
\hline SOBRESALIENTES & $0 \%$ & $0 \%$ & $0 \%$ \\
\hline NOTABLES & $37,5 \%(12)$ & $7,5 \%(3)$ & $37,5 \%(15)$ \\
\hline APROBADOS & $42,5 \%(17)$ & $92,5 \%(37)$ & $62,5 \%(25)$ \\
\hline SUSPENDIDOS & $20 \%(8)$ & $0 \%(0)$ & $0 \%(0)$ \\
\hline
\end{tabular}

* Total de alumnos que han participado: 40 
Fomento de la "Cultura Cientifica"en diferentes Grados y desde una perspectiva multidisciplinar.Descubrimientos científicos y su contexto filosófico-social

\subsection{Asignatura de Biotecnología Vegetal y Animal en el Grado de Biotecnología}

En la asignatura de Biotecnología Vegetal y Animal, que se imparte en el Grado de Biotecnología, han participado 9 alumnos repartidos en 3 grupos. Sus calificaciones se muestran en la Tabla 9.

Tabla 9. Calificación de la ficha y la noticia en la Asignatura de Biotecnología Vegetal y Animal en el Grado de Biotecnología

BIOTECNOLOGÍA VEGETAL Y ANIMAL_3 CURSO DEL GRADO BIOTECNOLOGÍA

\begin{tabular}{|c|l|c|c|c|}
\hline GRUPO & \multicolumn{1}{|c|}{ DESCUBRIMIENTO } & NOTA FICHA & $\begin{array}{c}\text { NOTA NOTICIA } \\
\text { (SEGUNDA ENTREGA) }\end{array}$ & NOTA TOTAL \\
\hline 1 & $\begin{array}{l}\text { LOS TRANSPOSONES O GENES SALTARINES, Bárbara MCClintock } \\
(1902-1992) \text { EEUU }\end{array}$ & 6.83 & 7.16 & $6.95=7.00$ \\
\hline 2 & $\begin{array}{l}\text { TELÓMEROS, TELOMERASA Y CÁNCER, } \\
\text { Elizabeth Helen Blackburn, (1948- 69 años) AUSTRALIA }\end{array}$ & 7.33 & 8.50 & 7.74 \\
\hline 3 & $\begin{array}{l}\text { LA PRIMERA FORMA DE VIDA ARTIFICIAL DE LA TIERRA } \\
\text { Jonh Craig Venter (1946---71 años) EEUU }\end{array}$ & 6,00 & 8.50 & 6.87 \\
\hline
\end{tabular}

\begin{tabular}{|l|c|c|c|}
\hline \multicolumn{1}{|c|}{ CALIFICACIONES } & NOTAS FICHA & NOTAS NOTICIA & NOTAS TOTALES \\
\hline SOBRESALIENTES & $0 \%(0)$ & $0 \%(0)$ & $0 \%(0)$ \\
\hline NOTABLES & $33,3 \%(1)$ & $100 \%(3)$ & $66,6 \%(2)$ \\
\hline APROBADOS & $66.6 \%(2)$ & $0 \%(0)$ & $33,3 \%(1)$ \\
\hline SUSPENDIDOS & $0 \%(0)$ & $0 \%(0)$ & $0 \%(0)$ \\
\hline
\end{tabular}

* Total de alumnos que han participado: 9

4.5 Calificaciones totales de todos los alumnos que han participado en el proyecto de Innovación.

La evaluación, tras las sucesivas correcciones y sugerencias a las entregas parciales efectuadas por los alumnos, arroja resultados satisfactorios. La tabla 10 evidencia una escasa incidencia de suspensos, tan sólo 14 de un total de 172 alumnos, por lo que se consideran alcanzados los objetivos del proyecto. 
Irene Sarrión Sos, Carmen Fagoaga García, Ángela Moreno Galvez, Enrique Eduardo Burguete Miguel, Ma Jesús Vega Bello y Gloría Ma Castellano Estornell

Tabla 10. Calificaciones totales de todos los alumnus que han participado en el proyecto de innovación

CALIFICACIONES TOTALES ALUMNOS PARA EL PROYECTO DE INNOVACIÓN

\begin{tabular}{|c|c|c|c|c|c|}
\hline & QUIMICA ORGÁNICA & $\begin{array}{c}\text { BIOLOGÍA VEGETAL Y } \\
\text { ANIMAL }\end{array}$ & FISIOLOGIA HUMANA & BIOQUÍMICA & TOTALES \\
\hline SOBRESALENTES & 21 & 0 & 3 & 0 & $14,53 \%(25)$ \\
\hline NOTABLES & 34 & 6 & 7 & 15 & $36,04 \%(62)$ \\
\hline APROBADOS & 31 & 3 & 9 & 25 & $39,53 \%(68)$ \\
\hline SUSPENSOS & 0 & 0 & 14 & 0 & $8,14 \%(14)$ \\
\hline TOTAL ALUMNOS & 86 & 9 & 37 & 40 & 172 \\
\hline TOTAL GRUPOS & 22 & 3 & 8 & 8 & 41 \\
& & & & & \\
\hline
\end{tabular}

\subsection{Resultados totales de la encuesta de valoración por parte de los alumnos del proyeco de innovación}

La Tabla 11 muestra los resultados de la encuesta de valoración del proyecto cumplimentada por los alumnus (ANEXO 5). En ella se toma en consideración su percepción sobre la dificultad, utilidad y grado de satisfacción en relación con el proyecto.

Tabla 11. Valoración total de la encuesta realizada por el alumnado en el proyecto de innovación

\begin{tabular}{|c|c|c|c|c|c|}
\hline $\begin{array}{l}\text { TODAS LAS ASIGNATURAS DISTINTOS GRADOS }(*) \\
\text { *Total alumnos encuestados } 172\end{array}$ & $\begin{array}{c}\text { Muy en } \\
\text { desacuerdo }\end{array}$ & En desacuerdo & De acuerdo & $\begin{array}{l}\text { Muy de } \\
\text { acuerdo }\end{array}$ & $\begin{array}{l}\text { No sabe, } \\
\text { no contesta }\end{array}$ \\
\hline $\begin{array}{l}\text { 1. El momento en que se planteó por parte del profesor el } \\
\text { trabajo a realizar a lo largo de la asignatura ha sido acertado }\end{array}$ & $\mathbf{0}$ & 0 & $\begin{array}{c}85 \\
(49,42 \%)\end{array}$ & $\begin{array}{c}87 \\
(50,58 \%)\end{array}$ & 0 \\
\hline 2. El tiempo de preparación del trabajo ha sido apropiado & 0 & $\begin{array}{c}8 \\
(4,65 \%)\end{array}$ & $\begin{array}{c}52 \\
(30,23 \%)\end{array}$ & $\begin{array}{c}112 \\
(65,12 \%)\end{array}$ & 0 \\
\hline $\begin{array}{l}\text { 3. ¿Has recibido información suficiente sobre las pautas y } \\
\text { directrices de cómo llevar a cabo el trabajo y la evaluación del } \\
\text { mismo (plantillas, rúbrica,...etc.)? }\end{array}$ & 0 & $\begin{array}{c}3 \\
(1,74 \%)\end{array}$ & $\begin{array}{c}92 \\
(53,49 \%)\end{array}$ & $\begin{array}{c}77 \\
(44,77 \%)\end{array}$ & 0 \\
\hline $\begin{array}{l}\text { 4. ¿Consideras que el trabajo está adecuadamente valorado en } \\
\text { el conjunto de la calificación final de la asignatura? }\end{array}$ & 0 & $\begin{array}{c}5 \\
(2,90 \%)\end{array}$ & $\begin{array}{c}55 \\
(31,98 \%)\end{array}$ & $\begin{array}{c}112 \\
(65,12 \%)\end{array}$ & 0 \\
\hline $\begin{array}{l}\text { 5. ¿Has aumentado tus conocimientos sobre los } \\
\text { descubrimientos científicos y la vida de los investigadores? }\end{array}$ & 0 & 0 & $\begin{array}{c}51 \\
(29,65 \%)\end{array}$ & $\begin{array}{c}121 \\
(70,35 \%)\end{array}$ & 0 \\
\hline $\begin{array}{l}\text { 6. Este trabajo ha contribuido a mejorar tu habilidad para } \\
\text { trabajar en grupo }\end{array}$ & 0 & $\begin{array}{c}5 \\
(2,90 \%)\end{array}$ & $\begin{array}{c}55 \\
(31,98 \%)\end{array}$ & $\begin{array}{c}112 \\
(65,12 \%)\end{array}$ & 0 \\
\hline 7. La publicación de la revista ha sido adecuada & 0 & 0 & $\begin{array}{c}112 \\
(65,12 \%) \\
\end{array}$ & $\begin{array}{c}60 \\
(34,88 \%) \\
\end{array}$ & 0 \\
\hline 8. El trabajo ha sido interesante & 0 & 0 & $\begin{array}{c}158 \\
(91,86 \%)\end{array}$ & $\begin{array}{c}14 \\
(8,14 \%) \\
\end{array}$ & 0 \\
\hline VALORACIÓN GLOBAL & Ninguna & Poca & Bastante & Mucha & $\begin{array}{l}\text { No sabe, } \\
\text { no contesta }\end{array}$ \\
\hline Dificultad & 0 & $\begin{array}{c}21 \\
(12,21 \%) \\
\end{array}$ & $\begin{array}{c}102 \\
(59,30 \%) \\
\end{array}$ & $\begin{array}{c}49 \\
(28,49 \%) \\
\end{array}$ & 0 \\
\hline Utilidad & 0 & 0 & $\begin{array}{c}151 \\
(87,79 \%) \\
\end{array}$ & $\begin{array}{c}21 \\
(12,21 \%) \\
\end{array}$ & 0 \\
\hline Satisfacción & 0 & 0 & $\begin{array}{c}160 \\
(93,02 \%)\end{array}$ & $\begin{array}{c}12 \\
(6,98 \%)\end{array}$ & 0 \\
\hline
\end{tabular}


Fomento de la "Cultura Científica"en diferentes Grados y desde una perspectiva multidisciplinar.Descubrimientos científicos y su contexto filosófico-social

\section{Conclusiones}

$\checkmark$ Los estudiantes, organizados en grupos de trabajo, han realizado un Dossier de "Fichas de Descubrimiento" y un Periódico de divulgación Científica abierto a la sociedad e impreso en papel.

$\checkmark$ Se ha promovido entre los estudiantes el aprendizaje de los conceptos científicos de las diferentes materias mediante la integración del proyecto en las diversas asignaturas de los grados, y a la vez se ha aportado la visión humana, ética y social de la ciencia.

$\checkmark \quad$ El diseño del proyecto ha propiciado que los alumnos comprueben por sí mismos que los científicos no son seres lejanos, aislados con sus experimentos, sino que los descubrimientos son resultado del trabajo en un entorno social, político y familiar.

$\checkmark$ Los alumnos han aprendido que la mayoría de los descubrimientos son con frecuencia resultado de una profundización sobre otras investigaciones realizadas bien por científicos que les han precedido, o bien por científicos contemporáneos.

$\checkmark$ Se ha destacado la importancia de que la sociedad tome conciencia del beneficio que produce un determinado descubrimiento, así como la dificultad que supone hacer llegar el conocimiento de un descubrimiento científico a un entorno social no especializado. El dar respuesta a esta problemática es lo que motiva la elaboración de la revista divulgativa.

$\checkmark$ Se ha empleado la metodología Flipped Classroom mediante la cual los alumnos han desarrollado habilidades para trabajar en equipo de forma autónoma, tales como: organización de tareas dentro de su grupo o asunción de roles en el mismo. Todo ello con el apoyo y orientación del profesorado. Esto ha favorecido las relaciones interpersonales tanto entre alumnos del mismo grupo de trabajo como entre grupos de alumnos de distintas materias y grados. También entre los profesores involucrados en el proyecto, que les han apoyado durante su aprendizaje.

$\checkmark \quad$ El proyecto ha resultado satisfactorio para el profesorado y para el alumnado de los diferentes grados. Tanto los alumnos como profesores se han implicado y el grado de motivación ha sido elevado.

$\checkmark$ El proyecto ha favorecido que, a través de asignaturas consideradas como de un perfil de ciencia básica o bien altamente técnico, en el seno de cada grado se trabajen competencias transversales que con frecuencia son difíciles de abordar desde estas materias.

$\checkmark$ La participación en el proyecto ha contribuido a mejorar la adquisición de competencias por parte de los alumnos en las materias implicadas. Ello se manifiesta en que la realización del trabajo ha redundado en una mejora de las calificaciones finales obtenidas por los alumnos en las asignaturas implicadas. 


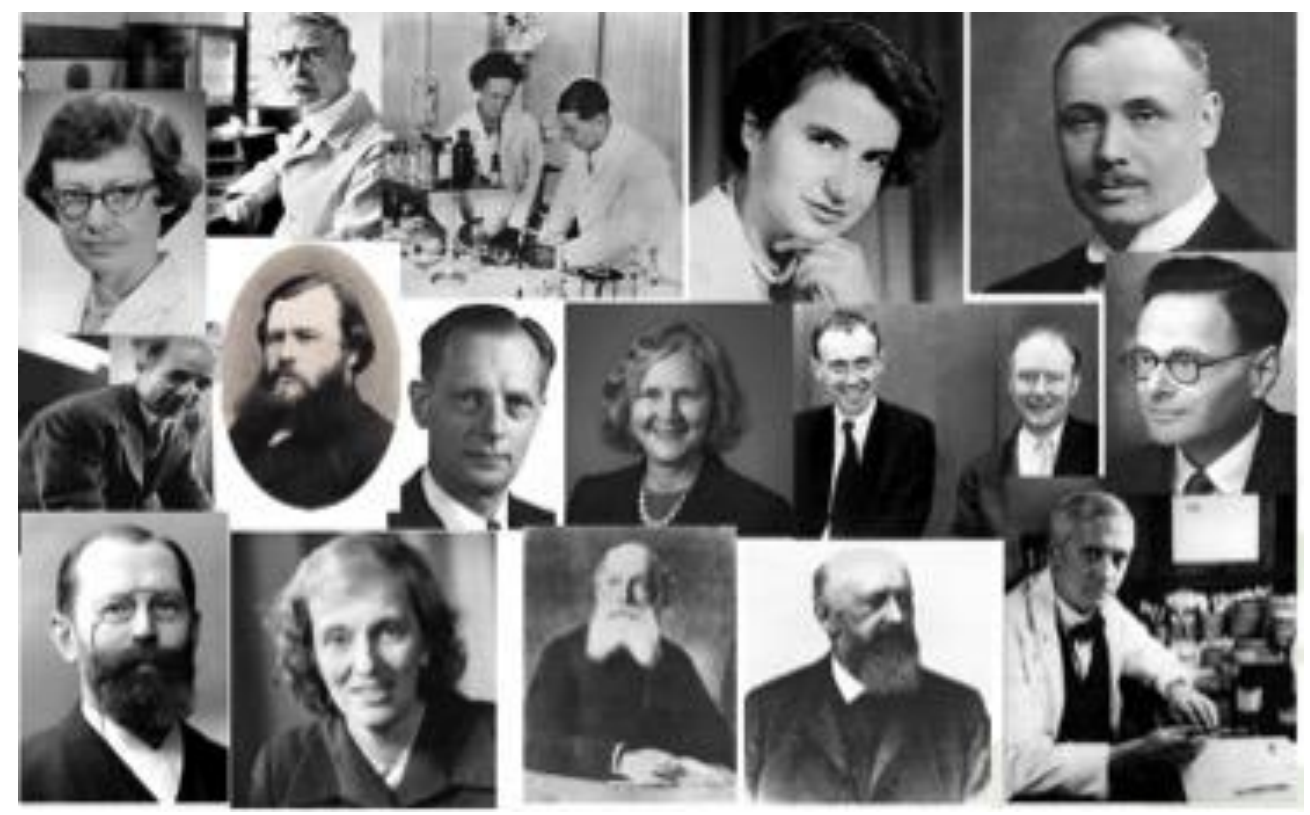

Fig. 19 Fotografias de algunos de los científicos que han sido objeto de estudio por parte de los alumnos que han participado en el trabajo de inovación cientifia

\section{Referencias bibliográficas.}

Briceño, F. (2001). La Historia de la Ciencia como referente en la investigación y didáctica de los contenidos científicos. Aula Ambiente. 1, pp. 87-92.

Díaz Rojo, J. \& Díaz Rojo, J. (2011). La circulación del saber científico en los siglos XIX y $X X$. Valencia: Instituto de Historia de la Medicina y de la Ciencia López Piñero.

Gagliardi, R. \& Giordan, A. (1986). La Historia de las Ciencias: Una herramienta para la Enseñanza . Enseñanza de las Ciencias.

Hammrich, P. \& Blouch, K. (1998). A cooperative controversy lesson designed to reveal students'conceptions of the Nature of Science. The American Biology Teacher. 60 (1), pp. 50-51

Matthews, M. (1994). Historia, Filosofía y enseñanza de las ciencias. España: Ice.

Scandroli, N. \& Rocha, A. (2002). Las concepciones de ciencia en docentes de enseñaza general básica (EBG): Un diagnóstico. Revista de Educación en Ciencia.Extremadura. 14 (3), pp. 289-302.

Solbes, J. \& Traver, M. (1998). La utilización de la historia de las ciencias en la enseñanza de la Física y la Química. España: Ice.

Velasco, J. (2008). Historia de la ciencia y enfoque historiográfico en libros de Ciencias Biológicas de Educación Básica y Educación Media Diversificada Profesional en Venezuela , Revista de Investigación . vol.32 no.64 ,pp. 63-84. 


\section{ANEXO 1}

DESCUBRIMIENTOS

CIENTÍFICOS Y SU

CONTEXTO

FILOSÓFICO Y

\section{SOCIAL.}

Fomento de la "Cultura

Cientifica" en diferentes

Grados y desde una

perspectiva multidisciplinar.

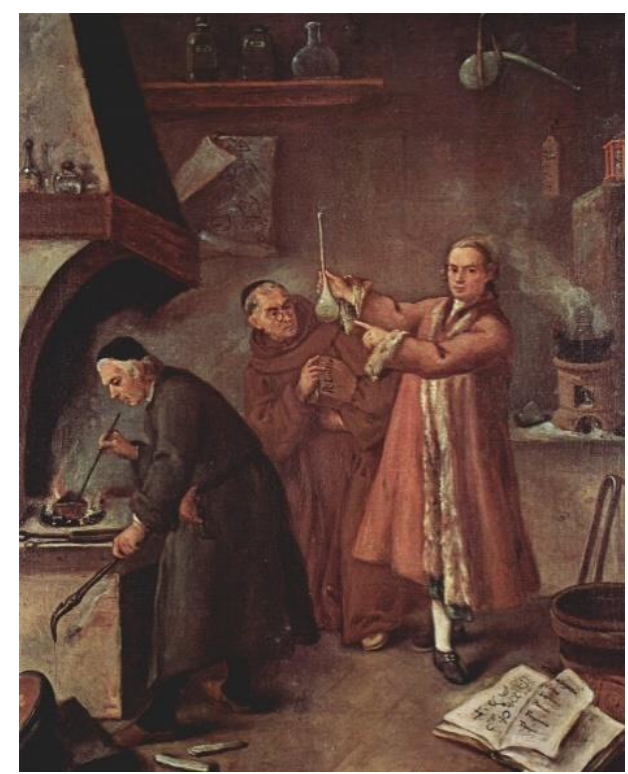

(Poned foto del descubrimiento)

Componentes del grupo:

Asignatura:

Profesor/profesora:

Grado:

Universidad

Católica

de Valencia 
1. Descubrimiento científico

Título del Descubrimiento:

Contenidos conceptuales. Descripción científica. 
2. Perfil bibliográfico del científico descubridor del mismo

Nombre del científico:

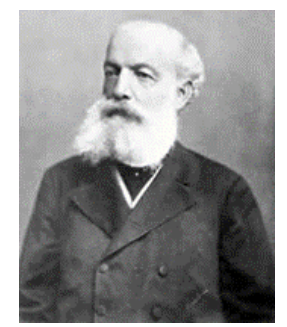

A. Cronología que recoja los principales aspectos de su vida y de su obra. Hechos más destacados.

B. Formación científica y principales influencias que recibió. Ideas dominantes de la Ciencia en la que se formó. Cuáles fueron sus maestros y marcos teóricos que existían en su época y que influyeron en su formación. Estado del arte en que se encontraban los problemas que más tarde abordó. 
3. Ciencia y la sociedad de su época. Contexto social y político que se vivia.

A. Influencia de la sociedad de su época en los desarrollos científicos. Principales acontecimientos, ideas sociales y politicas de la sociedad de su época.

B. Relaciones con sus contemporáneos: Otros científicos o personas relevantes de la sociedad de su época.

C. Otras aportaciones a la ciencia: Descubrimientos realizados y teorias elaboradas. Principales obras escritas por orden cronológico.

D. Aplicaciones tecnológicas e implicaciones sociales. Establecer un paralelismo cronológico que señale las interrelaciones entre la ciencia, la tecnología y la sociedad.

E. Bibliografia utilizada. Libros o artículos de revistas utilizados, materiales o documentos de apoyo entregados por el profesorado y utilizados. 


\section{ANEXO 2}

\section{Dossier}

\section{Descubrimientos científicos}

\section{TÍTULO DEL DESCUBRIMENTO CIENTÍFICO (Calibri 18)}

\section{Subtítulo (Calibri 14 negrita)}

¿Qué ha ocurrido?(Descubrimiento y lugar donde se ha descubierto) ¿Quién lo ha descubierto?

(Hablar un poco del investigador, relevancia científica, futuros proyectos)

Si hubiese un problema social y por ese motivo se ha investigado sobre ello se debe comentar (por/ejemplo: necesidad de vacunas por/problema con...)

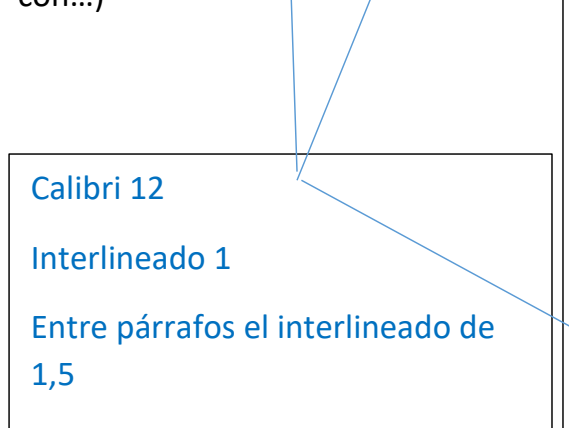

\section{Nombre y apellidos de los alumnos y año de la publicación}

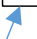

Fotografía/imagen

Pie de foto Calibri 11 


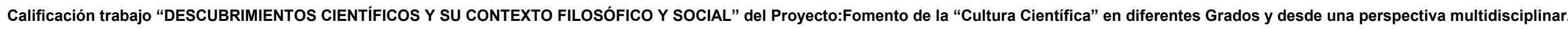

\begin{tabular}{|c|c|c|c|}
\hline GRADO/ASIGNATURA & \multicolumn{3}{|l|}{ APELLIDOS Y NOMBRE } \\
\hline \multicolumn{4}{|l|}{ ALUMNO } \\
\hline \multicolumn{4}{|l|}{ ALUMNO } \\
\hline \multicolumn{4}{|l|}{ ALUMNO } \\
\hline \multicolumn{4}{|l|}{ ALUMNO } \\
\hline COMPETENCIAS & 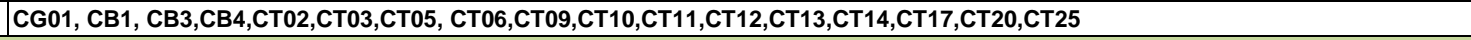 & & \\
\hline \multicolumn{4}{|c|}{ Valoración del FICHA DESCUBRIMIENTO/AUTOR 65\% } \\
\hline ESTRUCTURA DEL TRABAJO ESCRITO & RESULTADOS DE APRENDIZAJE (RE) R1,R4,R5,R6,R7 & $\begin{array}{l}\text { CALIFICACIÓN } \\
\text { PARCIAL }\end{array}$ & \multirow[t]{4}{*}{ CALIFICACIÓN } \\
\hline \multirow{3}{*}{$\begin{array}{l}\text { Organización del trabajo siguiendo los apartados indicados } \\
(10 \%)\end{array}$} & $\begin{array}{l}\text { Cumple con los requisitos establecidos: portada, estructura y secuencia de contenidos, formato márgenes justificados imagen investigador o hallazgo. } \\
\text { Cumple con los requisitos establecidos pero algunos de ellos no tiene la calidad total requerida }\end{array}$ & $\begin{array}{ll}3 \\
2\end{array}$ & \\
\hline & No cumple con todos los requisitos. Faltan algunos de ellos. & $\frac{2}{1}$ & \\
\hline & No es consistente o no siguió las indicaciones propuestas por el profesor para la presentación del trabajo. & 0 & \\
\hline \multirow{5}{*}{$\begin{array}{l}\text { Qué y cómo. Contenidos conceptuales. Descripción cientifica. } \\
(20 \%)\end{array}$} & RESULTADOS DE APRENDIZAJE (RE) R1,R4,R5,R6,R7 & & \\
\hline & Las ideas son claras, efectivas y pertinentes en todos los apartados & 3 & \\
\hline & Las ideas son claras y pertinentes en la mayoría de los apartados & 2 & \\
\hline & Las ideas son claras y pertinentes en algunos apartados & 1 & \\
\hline & Las ideas no son claras, ni pertinentes en los apartados & 0 & \\
\hline \multirow{4}{*}{$\begin{array}{l}\text { Quién. } \\
\text { Perfil Biográfico y científico. }(20 \%)\end{array}$} & Las ideas son claras, efectivas y pertinentes en todos los apartados & 3 & \\
\hline & Las ideas son claras y pertinentes en la mayoría de los apartados & 2 & \\
\hline & Las ideas son claras y pertinentes en algunos apartados & 1 & \\
\hline & Las ideas no son claras, ni pertinentes en los apartados & 0 & \\
\hline \multirow{4}{*}{$\begin{array}{l}\text { Cuando y donde. Ciencia y la sociedad de su época. Contexto } \\
\text { científico, social y politico que se vivia. (20\%) }\end{array}$} & Las ideas son claras, efectivas y pertinentes en todos los apartados & 3 & \\
\hline & Las ideas son claras y pertinentes en la mayoría de los apartados & 2 & \\
\hline & Las ideas son claras y pertinentes en algunos apartados & 1 & \\
\hline & Las ideas no son claras, ni pertinentes en los apartados & 0 & \\
\hline \multicolumn{4}{|c|}{ to } \\
\hline \multirow{3}{*}{ Fuentes de información y normativa de citación (10\%) } & Las fuentes de información son fiables, variadas y múltiples. Las Citas bibliográficas cumplen normativa APA/Vancouver & 3 & \\
\hline & Las Citas bibliográficas cumplen normativa APA/Vancouver pero las fuentes de información son limitadas o poco variadas. & 1,5 & \\
\hline & Las fuentes de información son muy pocas o ninguna. Son poco fiables y no contribuyen al tema. Las Citas bibliográficas no cumplen normativa APA/Vancouver & 0 & \\
\hline \multirow{3}{*}{$\begin{array}{l}\text { Ortografia (considerando como tales tanto errores ortográficos } \\
\text { como de puntuación y/o acentuación) (10\%) }\end{array}$} & No han cometido ningún error ortográfico & 3 & \\
\hline & Han cometido entre 1 y 5 errores ortográficos & 1,5 & \\
\hline & Han cometido más de 5 errores ortográficos & 0 & \\
\hline \multirow{4}{*}{ Uso de lenguaje disciplinar y argot especifico. (10\%) } & Utilizan el lenguaje adecuado,signos de puntuación y gramática en todo el trabajo & 3 & \\
\hline & Utilizan el lenguaje adecuado, signos de puntuación y gramática en la mayor parte del trabajo (más del 50\%) & 2 & \\
\hline & Utilizan el lenguaje adecuado,signos de puntuación y gramática adecuado en algunas partes del trabajo (menos del 50\%) & 1 & \\
\hline \multirow{2}{*}{\multicolumn{2}{|c|}{ SUBTOTAL CALIFICACION TRABAJO FICHA }} & 0 & \\
\hline & & & 0 \\
\hline & NOTA & & 0 \\
\hline
\end{tabular}




\section{ANEXO 4}

\section{DESCUBRIMIENTOS}

\section{CIENTÍFICOS Y SU CONTEXTO FILOSÓFICO Y SOCIAL}

Fomento de la cultura científica en diferentes

Grados desde una perspectiva multidisciplinar

CURSO 2017-2018

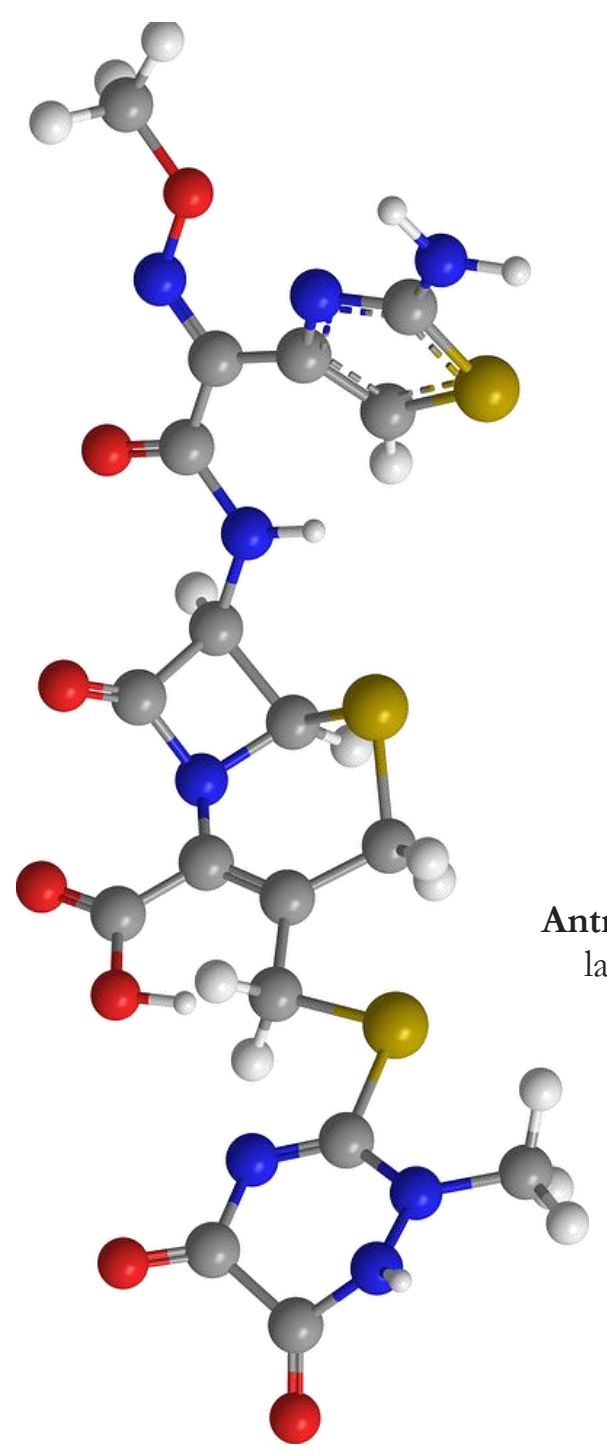

Trabajo realizado por alumnos en las asignaturas: Química Orgánica: Grado de Nutrición, Doble Grado NutriciónCiencias de la Actividad Física y Deporte, Grado de Biotecnología y Doble Grado Biotecnología-Ciencias del Mar. Profesora: Gloria $\mathbf{M}^{\mathrm{a}}$ Castellano Estornell

Biotecnología Vegetal y Animal: Grado de Biotecnología Profesora: Carmen Fagoaga García

Fisiología Humana: Grado de Ciencias de la Actividad Física y Deporte y Doble Grado Nutrición-Ciencias de la Actividad Física y Deporte Profesora: Irene Sarrión Sos

Bioquímica: Grado de Nutrición. Profesora: M $^{a}$ Jesús Vega Bello

Antropología: Grado de Nutrición, Doble Grado Nutrición-Ciencias de la Actividad Física y Deporte, Grado de Biotecnología y Doble Grado Biotecnología-Ciencias del Mar Profesor asesor: Enrique Burguete Miguel

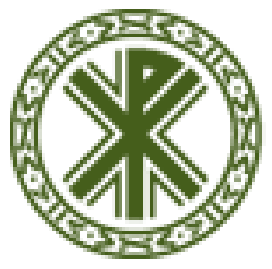

Universidad Católica de Valencia San Vicente Mártir 
Baeyer, Johann F. W. R. von (Síntesis fenoftaleina, aspirina y ácido barbitúrico) ........................

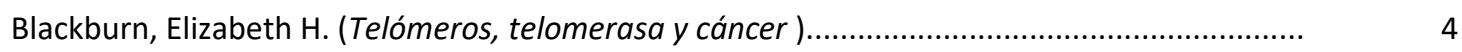

Borodín, Aleksandr (Reacción Borodin-Hunsdiecker) .........................................................

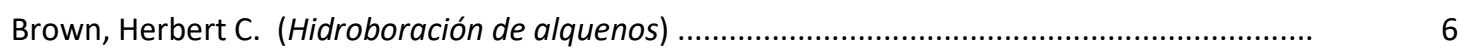

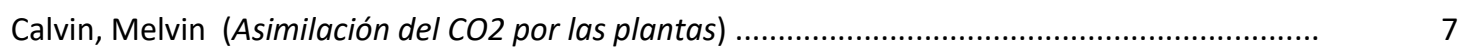

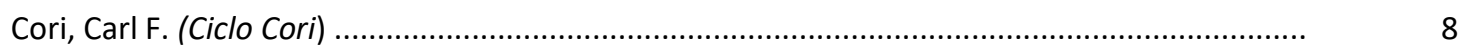

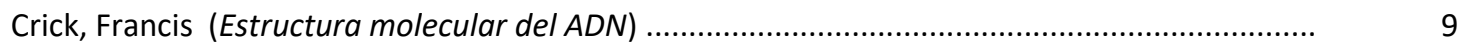

Diels, Otto P. H. (Reacción Diels-Alder) ............................................................................. 10

Elion, Gertrude B. (Primer tratamiento contra la Leucemia) .................................................... 11

Fischer, Hermann E. (Proyecciones de Fisher) .................................................................... 12

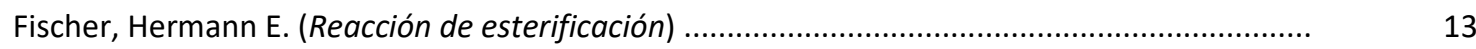

Fischer, Hermann E. (Ésteres, tintes y azúcares) .................................................................

Fleming, Alexander (Descubrimiento de la Penicilina) .............................................................. 15

Franklin, Rosalind (Estructura de doble hélice del ADN) ........................................................ 16

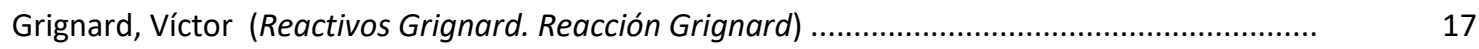

Hodgkin, Dorothy C. (Estructura de Moléculas complejas por cristalografía de Rayos X) ............. 18

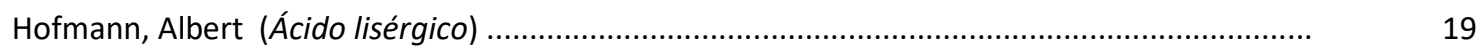

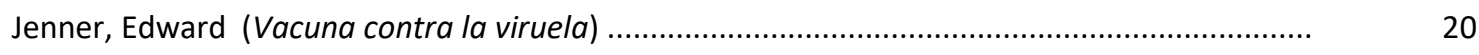

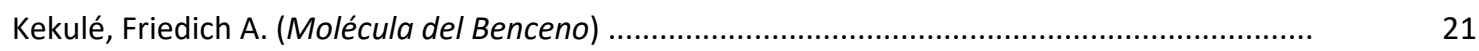

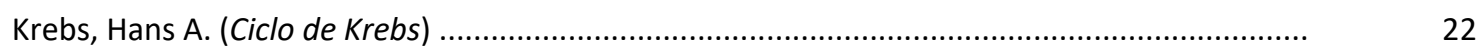

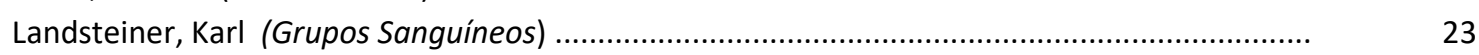

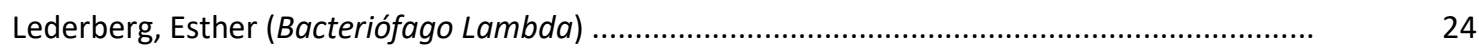

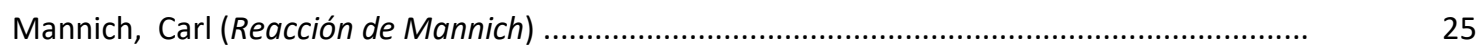

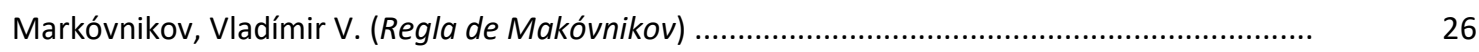

McClintock, Bárbara (Los transposones o genes saltarines) .................................................... 27

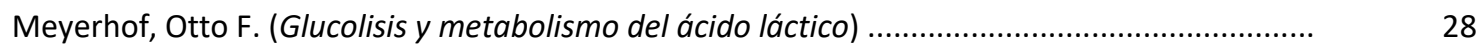

Northrop, John H. (Pepsina, tripsina, quimiotripsina y proteínas víricas) ....................................

Ochoa de Albornoz, Severo (Síntesis de ARN) ........................................................................... 30

Pasteur, Louis (Proceso de Pasteurización )......................................................................................

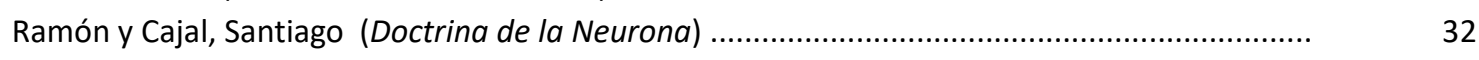

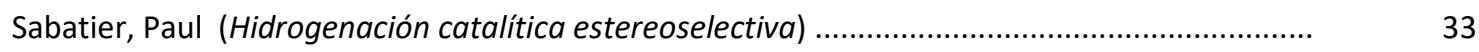

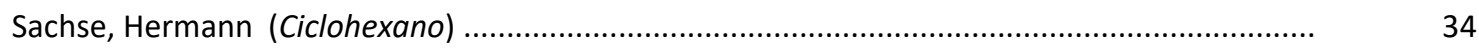

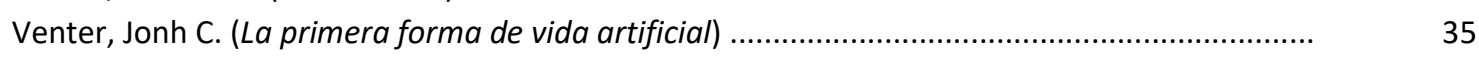

Watson, James D. (Estructura molecular de los ácidos nucleicos) .............................................. 36

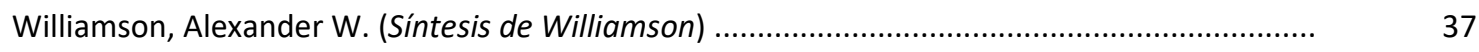

Williamson, Alexander W. (Reacciones de sustitución nucleófila SN1 y SN2) ............................

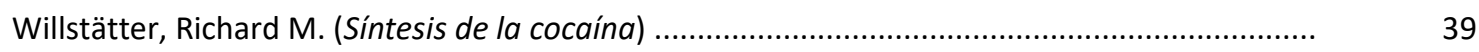

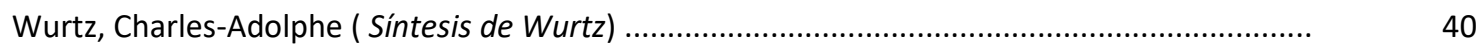

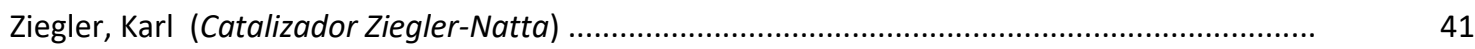




\section{ANEXO 4}

Willstätter, Richard M. (Síntesis de la cocaína) 


\title{
SE DESCUBRE QUE LA ESTRUCTURA DE LA MOLÉCULA DEL ADN ES UNA DOBLE HÉLICE
}

\author{
James Watson y Francis Crick concluyen que el modelo más acertado tiene que ser el de \\ una doble hélice. \\ NOMBRES ALUMNOS XXXXXXX.
}

Este hallazgo se refiere a que la doble hélice es donde se conservan en forma de secuencia los genes que contienen las instrucciones para sintetizar moléculas mayores que a su vez construyen células con funciones específicas, demostrando que la clave de la transmisión genética se oculta en el ADN.

El descubrimiento no es una mera descripción de la molécula, sino que permite comenzar a explicar el mecanismo con el que el ADN se separa en dos hebras - de ahí la doble hélicepara reproducirse en dos moléculas idénticas, la base de la herencia genética.

James Dewey Watson nace en Chicago (EEUU) el 6 de abril de 1928. A los 22 años acaba su doctorado en Zoología (1950) y desde 1951 a 1953 llega a la universidad de Cambridge, donde trabaja con el británico Francis Crick junto con físicos y químicos investigan las estructuras de las proteínas.

El joven científico de EEUU. intuye la importancia que puede tener esta desconocida molécula llamada ácido desoxirribonucleico o ADN, y la considera superior a la estructura de las proteínas, llegando a considerar que podría tratarse, de la mítica y ansiada molécula de la vida, responsable de la
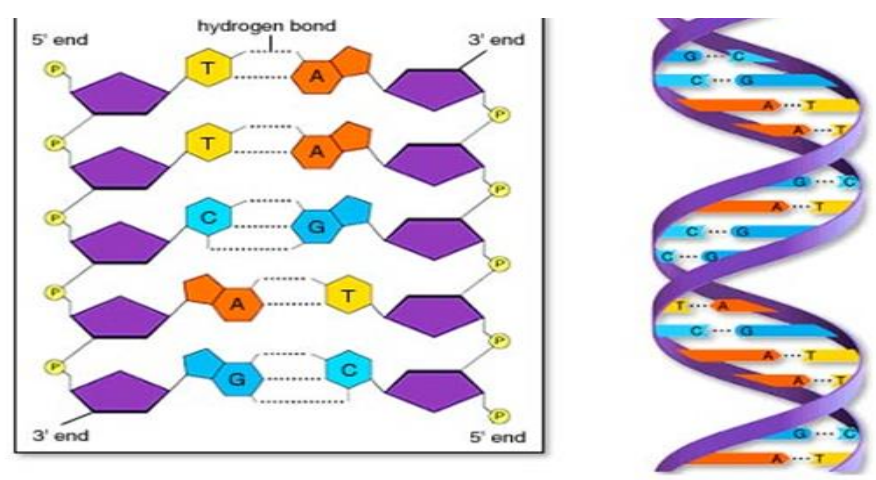

Estructura de doble hélice de la molécula de ADN transmisión de los caracteres hereditarios de los seres vivos.

En un congreso celebrado en Nápoles, Watson coincide con el físico Maurice Wilkins, que muestra una fotografía del $A D N$ obtenida mediante la técnica de difracción de rayos $X$. En ella se observa que el ADN parece poseer una estructura de forma regular. Watson se propone de desvelar las características del ADN asociándose con el investigador, Francis Crick.

Ambos dedican sus esfuerzos a interpretar las fotografías que Rosalind Franklin y Maurice Wilkins obtenidos mediante la difracción de rayos $X$. Convirtiéndose en una carrera contrarreloj porque Wilkins también trata de desentrañar el $A D N$ al otro lado del Atlántico. Intuyen que la estructura del ADN tiene que tratarse de una hélice. Manejando esta hipótesis, concluyen que el ADN está constituída por dos cadenas lineales enrolladas helicoidalmente entre sí. También se descubre la existencia de dos hebras complementarias, en función de sus bases nitrogenadas, era la clave. 
ANEXO 5

VALORACIÓN DEL TRABAJO

Universidad

Fecha trabajo de grupo : Curso Académico 2017-2018

Estimado estudiante.

La encuesta que a continuación te presentamos pretende evaluar la calidad del trabajo de grupo. La información que nos puedas aportar será muy valiosa para mejorarla. Agradecemos tu colaboración.

\begin{tabular}{|c|c|c|c|c|c|}
\hline & $\begin{array}{c}\text { Muy en } \\
\text { desacuerdo }\end{array}$ & $\begin{array}{c}\text { En } \\
\text { desacuerdo }\end{array}$ & $\begin{array}{l}\mathrm{De} \\
\text { acuerdo }\end{array}$ & $\begin{array}{l}\text { Muy de } \\
\text { acuerdo }\end{array}$ & $\begin{array}{l}\text { No } \\
\text { sabe, } \\
\text { no } \\
\text { contesta }\end{array}$ \\
\hline $\begin{array}{l}\text { 1. El momento en que se planteó por } \\
\text { parte del profesor el trabajo a realizar a } \\
\text { lo largo de la asignatura ha sido } \\
\text { acertado }\end{array}$ & 1 & 2 & 3 & 4 & 0 \\
\hline $\begin{array}{l}\text { 2. El tiempo de preparación del trabajo } \\
\text { ha sido apropiado }\end{array}$ & 1 & 2 & 3 & 4 & 0 \\
\hline $\begin{array}{l}\text { 3. ¿Has recibido información suficiente } \\
\text { sobre las pautas y directrices de cómo } \\
\text { llevar a cabo el trabajo y la evaluación } \\
\text { del mismo (plantillas, rúbrica,...etc.) ? }\end{array}$ & 1 & 2 & 3 & 4 & 0 \\
\hline $\begin{array}{l}\text { 4. ¿Consideras que el trabajo está } \\
\text { adecuadamente valorado en el } \\
\text { conjunto de la calificación final de la } \\
\text { asignatura? }\end{array}$ & 1 & 2 & 3 & 4 & 0 \\
\hline $\begin{array}{l}\text { 5. ¿Has aumentado tus conocimientos } \\
\text { sobre los descubrimientos científicos y } \\
\text { la vida de los investigadores? }\end{array}$ & 1 & 2 & 3 & 4 & 0 \\
\hline $\begin{array}{l}\text { 6. Este trabajo ha contribuido a mejorar } \\
\text { tu habilidad para trabajar en grupo }\end{array}$ & 1 & 2 & 3 & 4 & 0 \\
\hline $\begin{array}{l}\text { 7. La publicación de la revista ha sido } \\
\text { adecuada }\end{array}$ & 1 & 2 & 3 & 4 & 0 \\
\hline 8. El trabajo ha sido interesante & 1 & 2 & 3 & 4 & 0 \\
\hline VALORACIÓN GLOBAL & Ninguna & Poca & Bastante & Mucha & $\begin{array}{l}\text { No } \\
\text { sabe, } \\
\text { no } \\
\text { contesta }\end{array}$ \\
\hline Dificultad & 1 & 2 & 3 & 4 & 0 \\
\hline Utilidad & 1 & 2 & 3 & 4 & 0 \\
\hline Satisfacción & 1 & 2 & 3 & 4 & 0 \\
\hline
\end{tabular}

